\title{
Antecedents and enablers of supply chain reconfigurability and their effects on performance
}

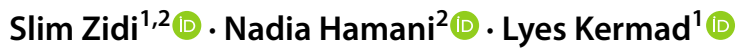 \\ Received: 6 October 2021 / Accepted: 30 January 2022 / Published online: 1 March 2022 \\ (c) The Author(s), under exclusive licence to Springer-Verlag London Ltd., part of Springer Nature 2022
}

\begin{abstract}
The reconfiguration of supply chain is becoming a crucial concept used to deal with market disruptions and changes such as the COVID-19 pandemic, demand uncertainty, and new technologies. It can be defined as the ability of the supply chain to change its structure and functions in order to adapt to new changes. Its assessment requires an understanding of its quantitative factors to provide indicators that are easy to interpret. Effective reconfigurability assessment can be achieved by measuring quantitatively its six characteristics (modularity, integrability, convertibility, diagnosability, scalability, and customization). This paper aims at identifying the quantitative factors of each characteristic and their inter-relationships by using Total Interpretive Structural Modelling (TISM). The structural model obtained by TISM is applied to understand the dependency quantitative factors. Based on TISM results, a classification of quantitative factors is determined using "Matrice d'Impacts Croisés, Multiplication Appliquée à un Classement" (MICMAC) analysis. This article provides a better understanding of the six characteristics previously mentioned to improve the reconfigurability of supply chains by considering the interactions between their factors. Thus, this analysis helps managers to understand the characteristics that influence the change of the supply chain structure and those that enable changing the supply chain functions in order to optimize the supply chain reconfiguration process.
\end{abstract}

Keywords Reconfigurable supply chain · Performance evaluation · Quantitative factors · Supply chain management · Reconfigurability $\cdot$ TISM $\cdot$ MICMAC

\section{Introduction}

Nowadays, the COVID-19 pandemic and many other hazards reveal the inability of the existing supply chains to cope with unforeseen risks. Consequently, several supply chain strategies need to be reconsidered. For example, reshoring is a core element in the supply chain reconfiguration strategy [1, 2]. It needs to be reconsidered to deal with the disruptions caused by the COVID 19 pandemic [3, 4]. In addition, supply

Slim Zidi

slim.zidi02@etud.univ-paris8.fr

Nadia Hamani

nadia.hamani@u-picardie.fr

Lyes Kermad

1.kermad@iut.univ-paris8.fr

1 QUARTZ Laboratory, University of Paris 8, 140 Rue de la Nouvelle France, Montreuil, France

2 Innovative Technologies Laboratory, University of Picardie Jules Verne, 48 Rue d'Ostende, 02100 Saint-Quentin, France chain uncertainties, demand fluctuations, and technological change are leading manufacturers to adapt the adequate supply that makes them competitive. To meet these challenges, the implementation of a Reconfigurable Supply Chain (RSC) ensures the survival of the company in changing environment $[5,6]$. RSC designates the ability of supply chain to change its structure and its functions to cope with disruptions. The latter is defined as unexpected events that impact the supply chain performance [7, 8]. Although disruption risks are rare events, they highly affect the supply chain [7, 9-12].

The changes affecting supply chain configuration are related to partner positions within the networks and the role of the central network organization [13]. Reconfiguration in supply chain combines a positive side indicating the innovation and the negative side indicating disruption risks, that is why it is important to innovate for disruption recovery [14]. In fact, the innovation is linked to the implementation of new technologies. [15] showed the crucial role of additive manufacturing technologies in supply chain reconfiguration strategies. RSC ensures the flexibility and agility 
of the supply chain by altering its configurations with the minimum resources [16]. Reconfigurability is characterized by modularity, convertibility, integrability, diagnosability, scalability, and customization $[17,18]$. These characteristics result in a truly reconfigurable supply chain [18]. Hence, it is necessary to assess the degree of reconfigurability through its characteristics to determine if the supply chain can easily and quickly change its structure and functions to cope with disruptions $[19,20]$. Several indicators have been proposed to measure reconfigurability for machine, cell, and system reconfiguration. However, the measuring of the supply chain capacity to cope with disruptions was not given great interest by the research community. In this paper, the previously mentioned reconfigurability characteristics are considered as the performance indicators for assessing the degree of reconfigurability. This assessment requires the identification of some factors to quantify each characteristic to help decisionmakers determine the capacity of their supply chains to cope with events that may affect the supply chain performance.

In [19], we proposed six metrics to measure the degree of reconfigurability by considering modularity, integrability, convertibility, diagnosability, scalability, and customization as key indicators of reconfigurability. In order to provide managers and decision-makers with a tool to quantitatively and objectively evaluate supply chain reconfigurability, while dealing with information uncertainty in the supply chain, [20] proposed a reconfigurability evaluation approach based on the six metrics using fuzzy logic.

The choice of reconfigurability characteristics as indicators to assess reconfigurability proved the possibility to effectively assess the ability of the supply chain to change its structure and functions to cope with market changes. For this purpose, we propose a detailed analysis of reconfigurability characteristics and its quantitative factors. The analysis aims to improve the reconfigurability evaluation model by studying the interactions between the quantitative factors related to reconfigurability characteristics that will give more details and data on them. Figure 1 illustrates the difference between our new approach in this article and our previous research work.

The purpose of this paper is to specify factors related to modularity, convertibility, integrability, diagnosability, scalability, and customization, which allows measuring the degree of reconfigurability.

The rest of the paper is organized as follows. In Sect. 2, the related works are surveyed. Section 3 presents the proposed methodology applied to identify the quantitative factors of each reconfigurability characteristic and analyze the inter-relationships between them. The obtained results are discussed in Sect. 4. Section 5 highlights the managerial and practical implications of the proposed approach. Finally, Sect. 6 concludes the paper.

\section{Literature review}

\subsection{The concept of reconfigurability}

Today's market environment is characterized by high competition and rapid change, which drives companies to implement new technologies that offer high flexibility and agility. New technologies are a major advantage for manufacturers in their strategies to adapt to changing market needs. Decision-makers are looking for these technologies to adjust their systems, from a structural and functional point of view to new requirements through dynamic reconfiguration. To remain competitive, manufacturing firms must respond quickly to fluctuating market demand by introducing products that meet customer needs [21]. In fact, the need to introduce new products, changing product structures, fluctuating demand, and the continuous emergence of new technologies have given rise to the concept of "Reconfigurability" manufacturing systems called Reconfigurable Manufacturing System (RMS) characterized by modularity, integrability, convertibility, diagnosability, and

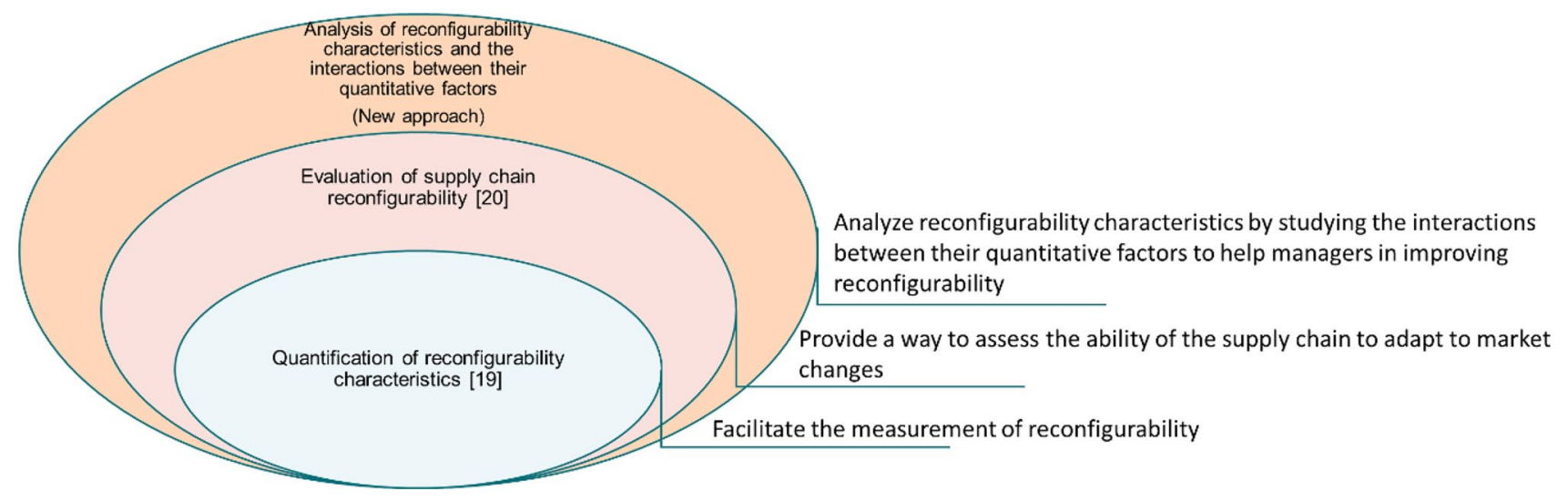

Fig. 1 The novelty of the proposed approach 
scalability [22]. Reconfigurability refers to the practical ability of a production or assembly system to change to a particular number of parts or sub-parts by adding or removing functional elements reactively and with minimal effort and delay [23]. Thus, it refers to the ability to repeatedly modify and reorganize the components of a system [24].

Reconfigurability represents a form of changeability that can be applied at the equipment, production system, and assembly system level to dynamically and efficiently change the capabilities and functionality of the system [25-27]. Beyond machines and system components, reconfigurability includes the ability to reconfigure resources quickly and efficiently to generate and deploy new configurations that cope with the new environment [28].

At a higher level, reconfigurability can be applied at the supply chain level. It is defined as the ability of supply chain to change its structure and its functions to cope with disruption and market changes [19, 29]. Indeed, the guarantee of reconfigurability is mainly due to its six characteristics that allow reducing the reconfiguration effort. [19, $20,30]$ consider that these characteristics allow judging and evaluating the capacity of the supply chain to adapt to the new requirements. Therefore, it is necessary to study the analogy between the characteristics at the RMS level and those at the RSC level.

From another point of view, the form of network governance can influence the dynamics of companies, namely the decision-making processes of supply chain reconfiguration [31]. Indeed, each company participating in a network must take into consideration the capabilities and specificities of other firms and how they can contribute to increasing the competitiveness of the network. In the same perspective, these effective sustainability strategies require the understanding of customers' needs and the resolution of problems quickly and efficiently, as highlighted by [32]. This shows that the reconfiguration of production networks and supply chains requires the assurance of effective sustainability. Some strategies have been evoked in the literature to point out the importance of the sustainability of production networks to support reconfiguration. [33] cited four strategies that guarantee the survival of firms in a changeable and risky environment:

- "Employment, training, and retention of high-quality staff members;

- Prevalence of good products, services, and optimum timing in introducing these into the marketplace;

- Excellent relationships with customers;

- Availability of top managers with good leadership qualities."

Some strategies can be deployed to support reconfiguration in order to be competitive, including environmental advantage, diversity, and consolidation. Indeed, in order to adapt to market changes and survive economic downturns [34], companies must adopt alignment strategies that focus on meeting customer needs by ensuring good communication with all stakeholders [35]. Second, the participative strategy focuses on idea creation by ensuring internal communication with employees. Also, the focus on ideas in case of lack of variety is called the simplistic strategy.

To remain competitive in an uncertain and competitive market, [31] studied the crucial elements for responding to these issues such as self-management for network configuration and development. At the level of resources and capabilities, the interactions between companies and the optimization of resources allow guaranteeing competitiveness. Concerning relationships and collaborations, the authors suggest establishing alliances between stakeholders. In this context, [36] mentioned that the development of information and communication technologies allows responding to market changes and remains competitive by ensuring cooperation strategies that guarantee information sharing. Finally, for the creation of value, it is recommended to create value through collaborative strategies to innovate and offer diversified products.

The choice of modularity, integrability, convertibility, diagnosability, scalability, and customization as indicators for measuring and evaluating reconfigurability has proved its effectiveness in the several case studies conducted in the context of RMS and RSC. Indeed, these case studies have been carried out in several industrial sectors that have implemented reconfigurable systems namely [37] which proposed a qualitative model that allows evaluating the degree of reconfigurability in an automotive company. In addition, [38] conducted a case study in an automotive industry to evaluate the reconfigurability of the system through its six characteristics. On a larger level, [39] proposed a model for evaluating reconfigurability in the supply chain that was implemented and tested in A multi-national automotive supply chain aimed at meeting the demand in the Indian market. Also, [20] conducted a case study in a pellet stove distribution company that decided to reconfigure its supply chain to meet the increased demand. In this case study, a comparison between two possible new configurations was proposed by evaluating their degree of reconfigurability according to the metrics proposed in [19].

\subsection{The characteristics of reconfigurability: from RMS to RSC}

\subsubsection{Modularity}

Modularity is generally used to reduce the complexity of the system through a decomposition based on the interactions existing between its components. In reconfigurable systems, it is measured through the degree of coupling, which 
designates the interactions between modules, and cohesion which indicates the interactions within modules [40-46]. The objective of modularity is to maximize cohesion and minimize coupling. In RSCs, modularity aims at clustering the activities of the supply chain by taking into account the flows connecting them [47]. It ensures the independence between modules through the standardization of interfaces $[48,49]$. In fact, the supply chain modularity is measured by the degree of non-proximity (geographic, organizational, cultural, and electronic) [50]. Quantitative factors proposed to measure the degree of modularity are the numbers of modules, the intra- and inter-module interactions, and the lead time.

\subsubsection{Convertibility}

To cope with disruptions, the system should be made up of components that can be easily converted to adapt quickly to new changes. In reconfigurable manufacturing systems, convertibility is measured based on the increment of conversion, the routing connections, and the replicated machines [51]. The system's capability to be autonomous is also a quantitative factor that must be considered to measure convertibility [52]. To easily convert supply chain components, it is necessary to have redundant entities to quickly deal with disruption [53]. Indeed, supply chain redundancy is the quantitative factor of convertibility measurement in RSC.

\subsubsection{Integrability}

Adjustment cost and time are key factors in measuring integrability in RMS [46]. They can be reduced by the standardization of interfaces. The complexity of the latter may, in turn, minimize the complexity of the supply chain composed of a set of nodes and flows that represent the connections between nodes [54, 55]. [56] explained the impact of product complexity on supply chain network that can negatively impact collaborative strategies with suppliers in the supply chain. It is due to a large number of actors and interconnections between them [57]. Quantitative factors allowing integrability measurement in RSC are number of nodes and number of connections.

\subsubsection{Diagnosability}

In order to detect and correct failures quickly, the reconfigurable system must have a high degree of RMS diagnosability that can be measured using the three following parameters:

- Detectability which determines the time before detecting the failure;
- Predictability which measures the time before the failure re-occurrence;

- Distinguishability which measures the time necessary to identify the replaceable unit of a system that causes a failure [42].

Diagnosability is also measured based on the accuracy of the quality tests on products during ramp-up time [46]. Indeed, the quality of the information transmitted in the system provides a better visibility on the system's state and, consequently, it allows a rapid detection of failures. In supply chain, this parameter is measured as a function of the quantity, accuracy, and freshness of the information [58]. Based on the above reasoning, RSC diagnosability is measured by considering two quantitative factors: supply chain visibility and detection time.

\subsubsection{Scalability}

In RMS, if the system is able to satisfy the customer demand with small capacity adjustments, then the RMS will have a high scalability and vice versa [46]. Scalability can be measured by the effectiveness of the system [59] and by the adjustment value needed to achieve the maximum capacity which depends on the reconfiguration cost and time [46]. Scalability in the supply chain depends on latency, the ability to achieve performance objectives in a dynamic and uncertain environment, and data quality [60]. The impact of scalability on supply chain performance can be expressed by delay [61]. Hence, RSC scalability can be measured by two quantitative factors: latency and throughput capacity.

\subsubsection{Customization}

Customization depends on customization activities showing customer involvement in the realization of products, which is a key factor that should be considered to measure the degree of customization in the supply chain [62]. Its degree can be increased by minimizing the response time [63, 64]. Indeed, customization can be measured based on several indicators such as [65] the value-added time, the throughput rate, and the average number of customizable functions. In RMS, two aspects must be taken into account in cutomization assessment: the product and the functionality which designates the machine utilization rate [46]. Based on this analysis, the quantitative factors of customization measurement are the response time and the number of customized functions.

As shown in Table 1, the identified quantitative factors of each RSC characteristic are summarized. 


\section{Proposed approach}

Literature studies were carried out to identify factors for a quantitative measure of reconfigurability characteristics. Based on the results presented in the literature review, the first stage of the proposed approach is to determine the interactions between all the quantitative factors of each RSC characteristic using the TISM method. An interaction is a mutual or reciprocal action or influence. It can be related to the enterprise internal flows and external flows linking all supply chain actors. These flows can be physical, informational, and financial. The second stage consists in identifying the most important quantitative factors. This classification allows identifying the most important characteristics in the supply chain reconfiguration process. Figure 2 shows the different steps of our approach.

Even if the TISM method requires the judgments of the decision-makers, the results of our approach will not be impacted by the subjectivity of this method because the identified relationships between the quantitative factors related to the reconfigurability characteristics do not impact the reconfigurability evaluation model. Indeed, our aim is to identify the possible interactions between the quantitative factors to better analyze the reconfigurability characteristics and to provide a way for managers to see the importance of each characteristic in improving reconfigurability. As pointed out by [16], configuration and reconfigurability problems are difficult to validate, and require the integration of decision-makers' judgments because the decision-making process is long.

\subsection{Development of inter-relationships among the quantitative factors using TISM}

The TISM method is applied to identify contextual relationships between the identified quantitative factors. It consists in defining the relationships between the quantitative factors, by developing structural and reachability matrices in order to classify the quantitative factors according to different levels.

\subsubsection{Development of the Structural Self-Interaction Matrix (SSIM)}

To determine the influences between the quantitative factors related to each reconfigurability characteristic, a questionnaire was conducted and addressed to a group of experts and academics. The questionnaire is used to analyze the influences between the identified factors, and thus to build SSIM. Eleven experts and academics participated in the questionnaire, where $36.4 \%$ have less than 10 years of experience, $36.4 \%$ also have experience between 10 and 20 years, while $27.3 \%$ have more than 20 years of experience. A classification of the experts' profiles is presented in Table 2.

This matrix is used to define any relationship between two quantitative factors. Four symbols are employed to indicate the direction of the relationship $(i, j)$, as shown in Table 3, with:

Table 1 Quantitative factors of RSC characteristics

\begin{tabular}{|c|c|c|c|}
\hline Characteristics & ID & Quantitative factors & Definition \\
\hline \multirow[t]{3}{*}{ Modularity } & M1 & Number of modules & The number of modules/units obtained after the modular decomposition \\
\hline & M2 & Intra- and inter-module interactions & $\begin{array}{l}\text { The number of links connecting the different modules and the elements of each } \\
\text { module }\end{array}$ \\
\hline & M3 & Lead time & $\begin{array}{l}\text { Corresponds to the time between the ordering of a supplier and the delivering of } \\
\text { goods to the customer }\end{array}$ \\
\hline Convertibility & $\mathrm{CO} 1$ & Supply chain redundancy & Consists in providing additional capacity to avoid delays or stops due to disruptions \\
\hline \multirow[t]{2}{*}{ Integrability } & I1 & Number of nodes & $\begin{array}{l}\text { Refers to the number of companies coordinating the management of goods } \\
\text { (purchase, stock, transport...) within the same supply chain }\end{array}$ \\
\hline & $\mathrm{I} 2$ & Number of connections & Refers to the number of interactions between the nodes of the supply chain \\
\hline \multirow[t]{2}{*}{ Diagnosability } & D1 & Supply chain visibility & Is the sharing of information in a just-in-time, reliable, and accurate manner \\
\hline & D2 & Detection time & $\begin{array}{l}\text { The time measured from the moment when a company realizes that it will be } \\
\text { affected by a supply chain disruption to the moment in which the incident really } \\
\text { occurs }\end{array}$ \\
\hline \multirow[t]{2}{*}{ Scalability } & $\mathrm{S} 1$ & Latency & It is the ratio between the delivery time and the throughput time \\
\hline & $\mathrm{S} 2$ & Throughput capacity & Designates the number of the performed orders \\
\hline \multirow[t]{2}{*}{ Customization } & CU1 & Response time & It is the total amount of time spent to respond to a request for service \\
\hline & CU2 & Number of customized functions & $\begin{array}{l}\text { Designates the number of functions related to the customization of the product/ } \\
\text { service }\end{array}$ \\
\hline
\end{tabular}


Fig. 2 Proposed approach of identification and analysis of the quantitative factors of RSC characteristics

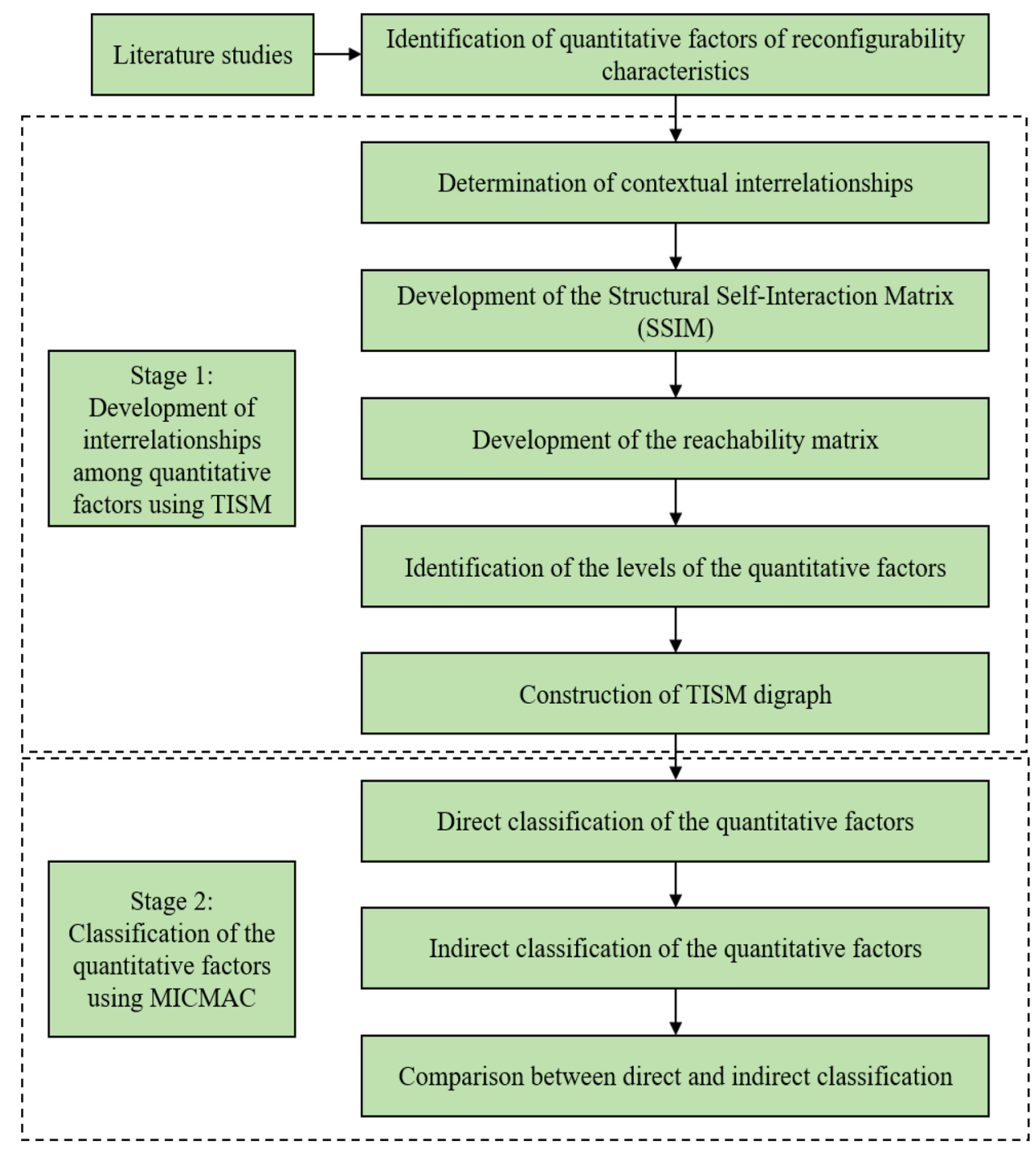

- V means that the quantitative factor $i$ "will influence" the quantitative factor $j$;

- A indicates that the quantitative factor $i$ "is influenced" by the quantitative factor $j$;

- $\mathrm{X}$ shows that the quantitative factors $i$ and $j$ influence each other;

Table 2 Expert's profile

\begin{tabular}{lll}
\hline Profile & Category & $\begin{array}{l}\text { Number } \\
\text { of experts }\end{array}$ \\
\hline Experience & Less than 10 years & $36.4 \%$ \\
& Between 10 and 20 years & $36.4 \%$ \\
Field & More than 20 years & $27.3 \%$ \\
& Supply chain & $90.9 \%$ \\
& Transport & $72.7 \%$ \\
& Production & $54.5 \%$ \\
& Academic & $18.2 \%$ \\
\hline
\end{tabular}

- O reveals that the quantitative factors $i$ and $j$ are not related.

\subsubsection{Development of the reachability matrix}

Based on the SSIM, we replace V, A, X, and O by 1 or 0 . The applied conversion rules are presented below:

- If the $(i, j)$ entry in the SSIM is V, then the $(i, j)$ entry in the reachability matrix is 1 and the $(j, i)$ entry is 0 ;

- If the $(i, j)$ entry in the SSIM is A, then the $(\mathrm{i}, \mathrm{j})$ entry in the reachability matrix is 0 and the $(j, i)$ entry is 1 ;

- If the $(i, j)$ entry in the SSIM is X, then the $(i, j)$ and $(j, i)$ entry in the reachability matrix is 1 ;

- If the $(i, j)$ entry in the SSIM is O, then the $(i, j)$ and $(j, i)$ entry in the reachability matrix is 0 .

The transitivity is also checked in the rules of the matrix. If a relationship exists between the first and second 
Table 3 Formation of SSIM

\begin{tabular}{llllllllllllll}
\hline & CU2 & CU1 & D2 & D1 & S2 & S1 & CO1 & I2 & I1 & M3 & M2 & M1 \\
\hline M1 & V & V & V & V & V & V & V & X & X & V & X & X \\
M2 & V & V & V & V & V & V & V & X & X & V & X & \\
M3 & A & A & O & O & X & X & O & A & A & X & & \\
I1 & V & V & V & V & V & V & V & X & X & & \\
I2 & V & V & V & V & V & V & V & X & & & \\
CO1 & O & O & V & V & O & O & X & & & & \\
S1 & O & O & O & O & X & X & & & & & \\
S2 & O & O & O & O & X & & & & & & \\
D1 & V & V & X & X & & & & & & & & \\
D2 & V & V & X & & & & & & & & & \\
CU1 & X & X & & & & & & & & & & \\
CU2 & X & & & & & & & & & & & \\
\hline
\end{tabular}

variable and between the second and third variable, then there is a relationship between the first and third variable. The obtained matrices are presented in Tables 4 and 5.

\subsubsection{Identification of the levels of the quantitative factors}

The obtained accessibility matrix is divided into reachability and antecedent sets, as shown in Tables 6, 7, 8, and 9.

\subsubsection{TISM model}

Quantitative factors are organized graphically in levels and directed links are represented according to the relationships identified in the reachability matrix. The relationship between elements $i$ and $j$ can be represented by an arc from $i$ to $j$. Figure 3 shows the structure of quantitative factors.

The number of modules, the number of interactions, the number of nodes, the number of inter- and intra-module interactions, and the supply chain redundancy are put at the bottom of the model, which means that these factors affect other factors and are not affected by none of them and are not influenced by any factors. Thus, they are very important and need to be primarily taken into account for a better reconfigurability in supply chains. At a higher level, supply chain visibility and detection time represent the second level. These factors interact with the next block constituted by the response time and the number of customized functions that represent the third level, which are homogeneous and influence each other. Finally, the lead time, latency, and throughput capacity are in the highest level of the TISM graph. Indeed, they are influenced by all the other enablers, and they affect them slightly.

\subsection{Classification of the quantitative factors using MICMAC analysis}

This stage consists in identifying the quantitative factors, i.e., those that are essential for the development of the system, first by direct classification (easy to implement) and then by indirect classification (by MICMAC). The MICMAC analysis is used to classify and validate the factors identified in the TISM.
Table 4 Initial reachability matrix

\begin{tabular}{lllllllllllll}
\hline & M1 & M2 & M3 & I1 & I2 & CO1 & S1 & S2 & D1 & D2 & CU1 & CU2 \\
\hline M1 & 1 & 1 & 1 & 1 & 1 & 1 & 1 & 1 & 1 & 1 & 1 & 1 \\
M2 & 1 & 1 & 1 & 1 & 1 & 1 & 1 & 1 & 1 & 1 & 1 & 1 \\
M3 & 0 & 0 & 1 & 0 & 0 & 0 & 1 & 1 & 0 & 0 & 0 & 0 \\
I1 & 1 & 1 & 1 & 1 & 1 & 1 & 1 & 1 & 1 & 1 & 1 & 1 \\
I2 & 1 & 1 & 1 & 1 & 1 & 1 & 1 & 1 & 1 & 1 & 1 & 1 \\
CO1 & 0 & 0 & 0 & 1 & 1 & 1 & 0 & 0 & 1 & 1 & 0 & 0 \\
S1 & 0 & 0 & 1 & 0 & 0 & 0 & 1 & 1 & 0 & 0 & 0 & 0 \\
S2 & 0 & 0 & 1 & 0 & 0 & 0 & 1 & 1 & 0 & 0 & 0 & 0 \\
D1 & 0 & 0 & 0 & 0 & 0 & 0 & 0 & 0 & 1 & 1 & 1 & 1 \\
D2 & 0 & 0 & 0 & 0 & 0 & 0 & 0 & 0 & 1 & 1 & 1 & 1 \\
CU1 & 0 & 0 & 1 & 0 & 0 & 0 & 0 & 0 & 0 & 0 & 1 & 1 \\
CU2 & 0 & 0 & 1 & 0 & 0 & 0 & 0 & 0 & 0 & 0 & 1 & 1 \\
\hline
\end{tabular}


Table 5 Final reachability matrix

\begin{tabular}{lllllllllllll}
\hline & M1 & M2 & M3 & I1 & I2 & CO1 & S1 & S2 & D1 & D2 & CU1 & CU2 \\
\hline M1 & 1 & 1 & 1 & 1 & 1 & 1 & 1 & 1 & 1 & 1 & 1 & 1 \\
M2 & 1 & 1 & 1 & 1 & 1 & 1 & 1 & 1 & 1 & 1 & 1 & 1 \\
M3 & 0 & 0 & 1 & 0 & 0 & 0 & 1 & 1 & 0 & 0 & 0 & 0 \\
I1 & 1 & 1 & 1 & 1 & 1 & 1 & 1 & 1 & 1 & 1 & 1 & 1 \\
I2 & 1 & 1 & 1 & 1 & 1 & 1 & 1 & 1 & 1 & 1 & 1 & 1 \\
CO1 & $1 *$ & $1 *$ & $1^{*}$ & 1 & 1 & 1 & $1 *$ & $1 *$ & 1 & 1 & $1 *$ & $1 *$ \\
S1 & 0 & 0 & 1 & 0 & 0 & 0 & 1 & 1 & 0 & 0 & 0 & 0 \\
S2 & 0 & 0 & 1 & 0 & 0 & 0 & 1 & 1 & 0 & 0 & 0 & 0 \\
D1 & 0 & 0 & $1 *$ & 0 & 0 & 0 & 0 & 0 & 1 & 1 & 1 & 1 \\
D2 & 0 & 0 & $1 *$ & 0 & 0 & 0 & 0 & 0 & 1 & 1 & 1 & 1 \\
CU1 & 0 & 0 & 1 & 0 & 0 & 0 & $1 *$ & $1 *$ & 0 & 0 & 1 & 1 \\
CU2 & 0 & 0 & 1 & 0 & 0 & 0 & $1 *$ & $1^{*}$ & 0 & 0 & 1 & 1 \\
\hline
\end{tabular}

The $1^{*}$ presented in Table 5 are included to incorporate transitivity

\subsubsection{Direct classification of the quantitative factors}

This step consists in filling the matrix of the direct influences, as shown in Table 6. Each element of this matrix is filled in according to the following scale:

- 0 means no influence;

- 1 means weak influence;

- 2 means medium influence;

- 3 means strong influence.

A first set of information can be obtained by analyzing the direct influences using the direct impact matrix. The sum of the values of each row and column indicates respectively the driving power and the dependency levels, as shown in Table 10.
The results of the direct influence matrix show that M1 (number of modules), M2 (number of inter- and intramodule interactions), I1 (number of nodes), I2 (number of interactions), and CO1 (supply chain redundancy) have the highest line sums; then, they represent the independent factors. In fact, M3 (lead time), S1 (latency), and S2 (throughput capacity) are dependent factors as they have the highest column sums.

Figure 4 shows the four quadrants indicating the four categories of factors obtained by the MICMAC analysis. The first quadrant includes the autonomous factors with low influence and low dependency such as D1 (supply chain visibility), D2 (detection time), CU1 (response time), and CU2 (number of customized functions). The second quadrant contains the dependent factors M3 (lead time), S1 (latency), and S2 (throughput capacity) having a low driving power

Table 6 Level partition (iteration I)

\begin{tabular}{|c|c|c|c|c|}
\hline Factors & Reachability set & Antecedent set & Intersection set & Level \\
\hline M1 & $\begin{array}{l}\text { M1, M2, M3, I1, I2, CO1, S1, S2, D1, D2, CU1, } \\
\text { CU2 }\end{array}$ & M1, M2, I1, I2, CO1 & M1, M2, I1, I2, CO1 & \\
\hline M2 & $\begin{array}{l}\text { M1, M2, M3, I1, I2, CO1, S1, S2, D1, D2, CU1, } \\
\text { CU2 }\end{array}$ & M1, M2, I1, I2, CO1 & M1, M2, I1, I2, CO1 & \\
\hline M3 & M3, S1, S2 & $\begin{array}{l}\text { M1, M2, M3, I1, I2, CO1, S1, S2, D1, D2, CU1, } \\
\text { CU2 }\end{array}$ & $\mathrm{M} 3, \mathrm{~S} 1, \mathrm{~S} 2$ & I \\
\hline I1 & $\begin{array}{l}\text { M1, M2, M3, I1, I2, CO1, S1, S2, D1, D2, CU1, } \\
\text { CU2 }\end{array}$ & M1, M2, I1, I2, CO1 & M1, M2, I1, I2, CO1 & \\
\hline $\mathrm{I} 2$ & $\begin{array}{l}\text { M1, M2, M3, I1, I2, CO1, S1, S2, D1, D2, CU1, } \\
\text { CU2 }\end{array}$ & M1, M2, I1, I2, CO1 & M1, M2, I1, I2, CO1 & \\
\hline $\mathrm{CO} 1$ & $\begin{array}{l}\text { M1, M2, M3, I1, I2, CO1, S1, S2, D1, D2, CU1, } \\
\text { CU2 }\end{array}$ & M1, M2, I1, I2, CO1 & M1, M2, I1, I2, CO1 & \\
\hline S1 & $\mathrm{M} 3, \mathrm{~S} 1, \mathrm{~S} 2$, & M1, M2, M3, I1, I2, CO1, S1, S2, CU1, CU2 & $\mathrm{M} 3, \mathrm{~S} 1, \mathrm{~S} 2$, & I \\
\hline S2 & $\mathrm{M} 3, \mathrm{~S} 1, \mathrm{~S} 2$, & M1, M2, M3, I1, I2, CO1, S1, S2, CU1, CU2 & M3, S1, S2, & I \\
\hline D1 & M3, D1, D2, CU1, CU2 & M1, M2, I1, I2, CO1, D1, D2 & D1, D2 & \\
\hline D2 & M3, D1, D2, CU1, CU2 & M1, M2, I1, I2, CO1, D1, D2 & D1, D2 & \\
\hline CU1 & M3, S1, S2, CU1, CU2 & $\mathrm{M} 1, \mathrm{M} 2, \mathrm{I} 1, \mathrm{I} 2, \mathrm{CO} 1, \mathrm{D} 1, \mathrm{D} 2, \mathrm{CU} 1, \mathrm{CU} 2$ & CU1, CU2 & \\
\hline CU2 & M3, S1, S2, CU1, CU2 & M1, M2, I1, I2, CO1, D1, D2, CU1, CU2 & CU1, CU2 & \\
\hline
\end{tabular}


Table 7 Level partition (iteration II)

\begin{tabular}{llll}
\hline Factors & Reachability set & Antecedent set & Intersection set \\
\hline M1 & M1, M2, I1, I2, CO1, D1, D2, CU1, CU2 & M1, M2, I1, I2, CO1 & M1, M2, I1, I2, CO1 \\
M2 & M1, M2, I1, I2, CO1, D1, D2, CU1, CU2 & M1, M2, I1, I2, CO1 & M1, M2, I1, I2, CO1 \\
I1 & M1, M2, I1, I2, CO1, D1, D2, CU1, CU2 & M1, M2, I1, I2, CO1 & M1, M2, I1, I2, CO1 \\
I2 & M1, M2, I1, I2, CO1, D1, D2, CU1, CU2 & M1, M2, I1, I2, CO1 & M1, M2, I1, I2, CO1 \\
CO1 & M1, M2, I1, I2, CO1, D1, D2, CU1, CU2 & M1, M2, I1, I2, CO1 & M1, M2, I1, I2, CO1 \\
D1 & D1, D2, CU1, CU2 & M1, M2, I1, I2, CO1, D1, D2 & D1, D2 \\
D2 & D1, D2, CU1, CU2 & M1, M2, I1, I2, CO1, D1, D2 & D1, D2 \\
CU1 & CU1, CU2 & M1, M2, I1, I2, CO1, D1, D2, CU1, CU2 & CU1, CU2 \\
CU2 & CU1, CU2 & M1, M2, I1, I2, CO1, D1, D2, CU1, CU2 & CU1, CU2 \\
\hline
\end{tabular}

and a high dependency power. The third quadrant contains no factors which consists of the linking factors having high driving and dependency power. The fourth quadrant involves the independent factors with high influence and low dependency, such as M1 (number of modules), M2 (intra- and intermodule interactions), I1 (number of nodes), I2 (number of connections between nodes), and CO1 (supply chain redundancy). From the direct influence matrix, MICMAC generates a graph showing the most important influences, as shown in Fig. 5.

\subsubsection{Indirect classification of the quantitative factors}

The analysis of the indirect relationships allows detecting the essential and hidden factors and classifying the variables according to their influences by considering the global network of the relations described by the structural analysis matrix. The MICMAC analysis examines the influences between the variables to determine the indirect effects. These results show that the enablers M1 (number of modules), M2 (number of interactions between and within modules), I1 (number of nodes), I2 (number of interactions), and CO1 (supply chain redundancy) are driving enablers since they have the largest sum of lines. While M3 (lead time), S1 (latency), and S2 (throughput capacity) are the most influenced enablers (also called dependent enablers) because they have the highest sum of column. Table 11 summarizes the obtained results.
These results reveal that the enablers M1 (number of modules), M2 (number of inter- and intra-module interactions), I1 (number of nodes), I2 (number of interactions), and CO1 (supply chain redundancy) are driving enablers as they have the largest sums of lines. On the other hand, M3 (lead time), I1 (latency), and I2 (throughput capacity) are the most influenced enablers (also called dependent enablers) because they have the highest column sums.

The influential enablers and linking enablers are the same as those of the direct influence map. According to the indirect influence design, all factors keep the same position as in the direct design as demonstrated in Fig. 6. The influences of all the factors are represented in Fig. 7.

\subsubsection{Comparison between direct and indirect classification}

A comparison of the hierarchy of the quantitative factors of supply chain reconfigurability in the different classifications (direct and indirect) validates the importance of certain factors such as number of nodes, number of connections, number of modules, and supply chain redundancy in the supply chain reconfigurability assessment process.

MICMAC allows calculating numerical weights (direct influences/dependencies and indirect influences/dependencies) of reconfigurability enablers in supply chains and classifying them in descending order, as exposed in Tables 12 and 13.

From this comparison, we notice that enablers do not keep their rankings in the classification according to
Table 8 Level partition (iteration III)

\begin{tabular}{lllll}
\hline Factors & Reachability set & Antecedent set & Intersection set & Level \\
\hline M1 & M1, M2, I1, I2, CO1, D1, D2 & M1, M2, I1, I2, CO1 & M1, M2, I1, I2, CO1 & IV \\
M2 & M1, M2, I1, I2, CO1, D1, D2 & M1, M2, I1, I2, CO1 & M1, M2, I1, I2, CO1 & IV \\
I1 & M1, M2, I1, I2, CO1, D1, D2 & M1, M2, I1, I2, CO1 & M1, M2, I1, I2, CO1 & IV \\
I2 & M1, M2, I1, I2, CO1, D1, D2 & M1, M2, I1, I2, CO1 & M1, M2, I1, I2, CO1 & IV \\
CO1 & M1, M2, I1, I2, CO1, D1, D2 & M1, M2, I1, I2, CO1 & M1, M2, I1, I2, CO1 & IV \\
D1 & D1, D2 & M1, M2, I1, I2, CO1, D1, D2 & D1, D2 & III \\
D2 & D1, D2 & M1, M2, I1, I2, CO1, D1, D2 & D1, D2 & III \\
\hline
\end{tabular}


Table 9 Level partition (iteration IV)

\begin{tabular}{lllll}
\hline Factors & Reachability set & Antecedent set & Intersection set & Level \\
\hline M1 & M1, M2, I1, I2, CO1 & M1, M2, I1, I2, CO1 & M1, M2, I1, I2, CO1 & IV \\
M2 & M1, M2, I1, I2, CO1 & M1, M2, I1, I2, CO1 & M1, M2, I1, I2, CO1 & IV \\
I1 & M1, M2, I1, I2, CO1 & M1, M2, I1, I2, CO1 & M1, M2, I1, I2, CO1 & IV \\
I2 & M1, M2, I1, I2, CO1 & M1, M2, I1, I2, CO1 & M1, M2, I1, I2, CO1 & IV \\
CO1 & M1, M2, I1, I2, CO1 & M1, M2, I1, I2, CO1 & M1, M2, I1, I2, CO1 & IV \\
\hline
\end{tabular}

direct and indirect influences and dependencies. Factors M1, M2, D1, D2, CU1, and CU2 have changed their rank in the indirect influence classification and have moved to higher ranks, which prove the importance of the indirect effect of these factors on the other factors. The green lines show the advancement in rank of the factors, while the red lines indicate its degradation. Moreover, we notice that the factors $\mathrm{CO} 1, \mathrm{I} 1, \mathrm{I} 2$, and $\mathrm{M} 3$ moved to lower ranks in the indirect influence classification. The influence of this factor decreases relatively when the indirect influences are considered. This classification allowed clarifying and validating the classification of factors obtained with TISM. Figure 8 represents the most highly reclassified factors and the rank variations for the most dependent factors. The variation in the positions of the enablers between their initial positions and their final positions is shown in Fig. 9.

This plan, represented in Fig. 9, shows the displacement of the influences of the factors which designates the change of the degrees of influence between the direct and indirect plans of the influences/dependencies. The results of the direct and indirect influences/dependencies analysis can be classified according to a comparison between the driving and dependent factors at the direct and indirect levels, as shown in Table 14. We note that all the factors kept their same position in the quadrants of the influence and dependency maps despite the variation in their degrees of influence.

\section{Results and discussion}

The aim of this study is to analyze and develop a model of mutual influences and relationship among factors allowing the assessment of reconfigurability. First, 12 quantitative factors were identified based on the literature. They were chosen based on each characteristic (modularity, integrability, convertibility, diagnosability, scalability, and customization) in order to facilitate their quantitative evaluations. To develop the SSIM matrix, a questionnaire was given to 11 experts and academics to determine the influences of all the identified factors. Then, the MICMAC analysis presents substantial information on the importance and interdependencies of these factors.

The TISM results show that the number of modules (M1), the number of inter- and intra-modules (M2), the number of nodes (I1), the number of connections (I2), and the supply chain redundancy $(\mathrm{CO} 1)$ are factors that affect the other factors, but they are not influenced by any other factor. In fact, they influence the factors of the highest level including supply chain visibility (D1) and detection time (D2) that affect the factors of the second level: response time (CU1) and number of customized function (CU2). The highest level is composed of lead time, latency, and throughput capacity that represent factors not influencing any other factor. These findings were verified and validated by the MICMAC analysis. Based on the results obtained by the direct and
Fig. 3 TISM model for the quantitative factors of the RSC characteristics

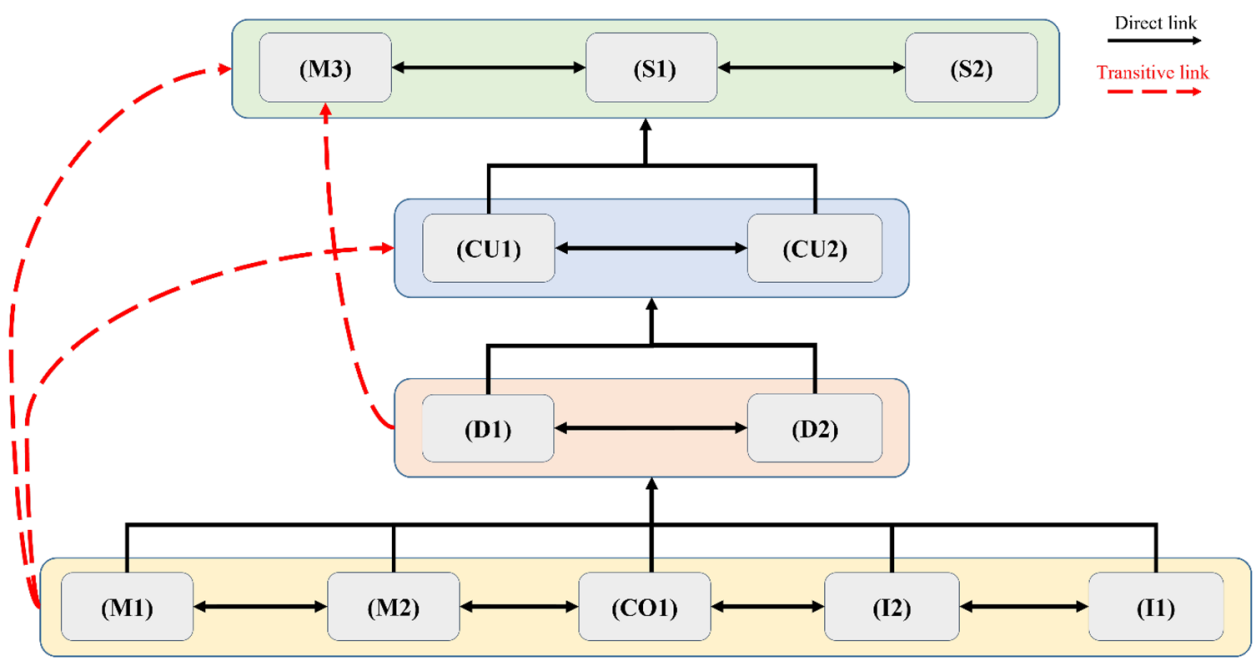


Table 10 Direct influence matrix

\begin{tabular}{llllllllllllll}
\hline & M1 & M2 & M3 & I1 & I2 & CO1 & S1 & S2 & D1 & D2 & CU1 & CU2 & Sum \\
\hline M1 & 0 & 3 & 3 & 3 & 3 & 3 & 1 & 1 & 2 & 2 & 1 & 1 & 22 \\
M2 & 1 & 0 & 1 & 1 & 1 & 1 & 1 & 1 & 2 & 2 & 1 & 1 & 22 \\
M3 & 0 & 0 & 0 & 0 & 0 & 0 & 1 & 1 & 0 & 0 & 0 & 0 & 6 \\
I1 & 3 & 3 & 2 & 0 & 3 & 2 & 1 & 1 & 3 & 2 & 1 & 1 & 24 \\
I2 & 3 & 3 & 2 & 3 & 0 & 2 & 1 & 1 & 3 & 2 & 1 & 1 & 24 \\
CO1 & 3 & 3 & 3 & 2 & 2 & 0 & 1 & 1 & 2 & 1 & 1 & 1 & 24 \\
S1 & 0 & 0 & 2 & 0 & 0 & 0 & 0 & 3 & 0 & 0 & 0 & 0 & 5 \\
S2 & 0 & 0 & 2 & 0 & 0 & 0 & 3 & 0 & 0 & 0 & 0 & 0 & 5 \\
D1 & 0 & 0 & 1 & 0 & 0 & 0 & 0 & 0 & 0 & 3 & 1 & 1 & 6 \\
D2 & 0 & 0 & 1 & 0 & 0 & 0 & 0 & 0 & 3 & 0 & 1 & 1 & 6 \\
CU1 & 0 & 0 & 1 & 0 & 0 & 0 & 1 & 1 & 0 & 0 & 0 & 3 & 6 \\
CU2 & 0 & 0 & 1 & 0 & 0 & 0 & 1 & 1 & 0 & 0 & 3 & 0 & 6 \\
Sum & 12 & 12 & 21 & 11 & 11 & 10 & 17 & 17 & 13 & 12 & 10 & 10 & \\
\hline
\end{tabular}

indirect classifications according to the driving power and the dependency levels, M1, M2, I1, I2, and CO1 are independent factors, while S1, S2, and M3 are dependent factors.

The reconfigurability of supply chains can be related to two main structural and functional aspects. The structural aspect consists in changing the structure of the supply chain related to its design nature. On the other hand, the functional aspect is related to value creation aiming at improving the supply chain functions (purchasing, storage, flow management, etc.). Indeed, M1, M2, I1, I2, and CO1 are factors related to the structural design changes of the supply chain. Thus, modularity, integrability, and convertibility are characteristics that affect the components of the supply chain: the nodes, which represent suppliers, factories, distribution centers, etc., and the connections that designate the information and physical flows linking the nodes. These elements (nodes and connections) form the structural design of the supply chain. Figure 10 shows the interactions between the reconfigurability characteristics based on their evaluation factors.

\section{Managerial and practical implications}

The aim of this study is to identify and analyze the quantitative factors considered to evaluate the reconfigurability in supply chains. This analysis allows managers and decisionmakers to know the most important factors in both the evaluation and implementation of reconfigurability. Indeed, these factors were identified, in the literature, according to the six characteristics of reconfigurability (modularity, integrability, convertibility, diagnosability, scalability, and customization). They also allow successfully implementing a RSC.

The factor analysis helped prioritize and classify the quantitative factors and consequently the reconfigurability characteristics. Indeed, the number of modules, the number of intra- and inter-module interactions, the number of nodes, and the number of connections between them as well as the supply chain redundancy represent the independent factors that influence the other factors. These factors show the importance of modularity, integrability, and convertibility
Fig. 4 Direct influence/dependence map

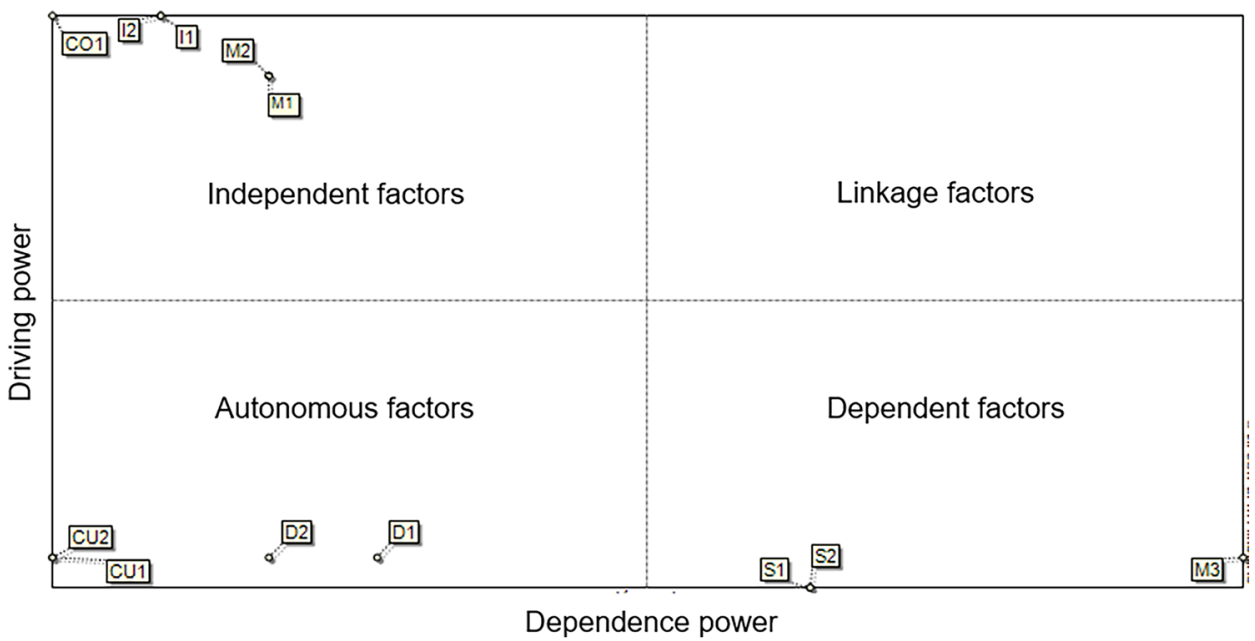


Fig. 5 Graph representing direct influence

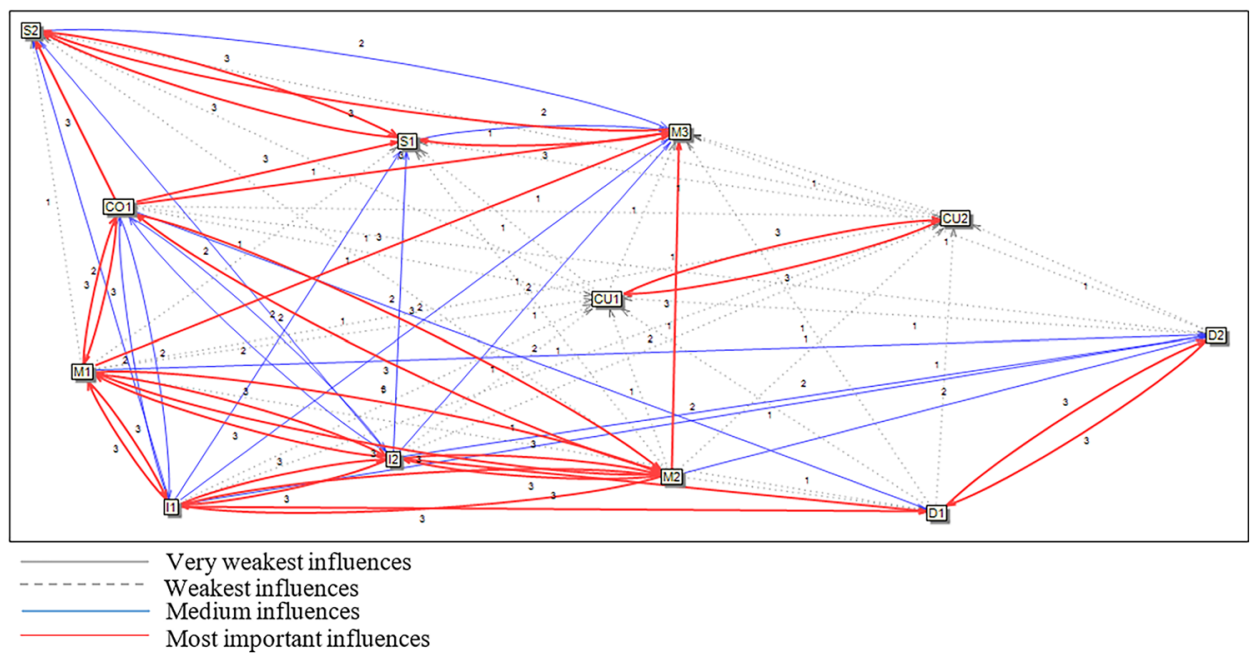

in designing a RSC. These characteristics mainly impact the structural change of the supply chain. Indeed, improving the supply chain degree of reconfigurability requires modular design, reducing the degree of complexity, which depends on the number of nodes and connections, and increasing the redundancy of the supply chain. On the other hand, the supply chain visibility, related to the quantity and quality of the information shared between all the actors of the chain, and the detection time depend highly on the supply chain structure. Indeed, the less complex the supply chain is, the higher the visibility and the faster the detection time of failures will be. In addition, factors related to customization (response time and number of customized functions) depend on the supply chain structure. Thus, the modular design must be oriented towards mass customization. Finally, lead time,

Table 11 Driving and dependency power values of the indirect influence matrix

\begin{tabular}{lll}
\hline & Row total & Column total \\
\hline M1 & 4214 & 1494 \\
M2 & 4214 & 1494 \\
M3 & 162 & 3077 \\
I1 & 3772 & 1292 \\
I2 & 4046 & 1399 \\
CO1 & 4046 & 1399 \\
S1 & 206 & 1669 \\
S2 & 206 & 1582 \\
D1 & 141 & 2807 \\
D2 & 141 & 2807 \\
CU1 & 186 & 1250 \\
CU2 & 186 & 1250 \\
& 156 & 156 \\
\hline
\end{tabular}

latency, and throughput capacity are factors influenced by other factors and do not influence other factors. This classification allows understanding the impact of each factor on the evaluation of the supply chain reconfigurability and how to improve its degree through structural and functional changes.

The objective of our approach is to perform a detailed and methodological analysis of the reconfigurability characteristics and their identified quantitative factors. This analysis allows knowing the impact of each factor related to each characteristic on supply chain reconfigurability. This theoretical approach offers practical implications for managers and decision-makers in implementing a reconfigurable supply chain or improving reconfigurability. As an example, the results of our approach show that modularity and integrability allow reconfiguring the supply chain structure by decomposing the supply chain activities into a set of independent modules and reducing its structural complexity. In this example, we show managers that by implementing a

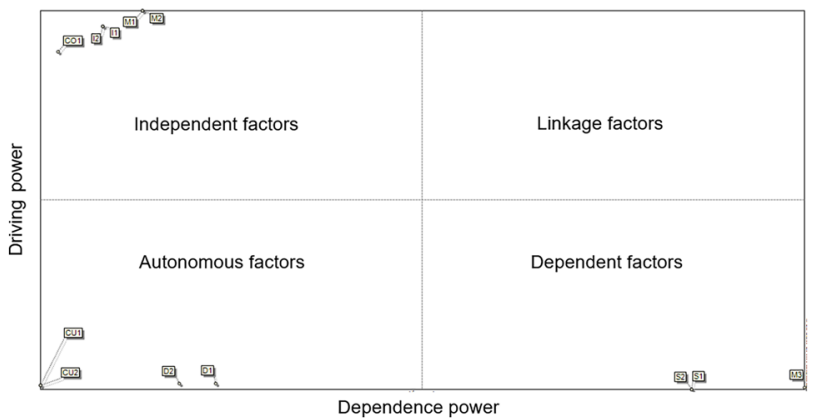

Fig. 6 Indirect influence/dependence map 
Fig. 7 The graph representing indirect influence

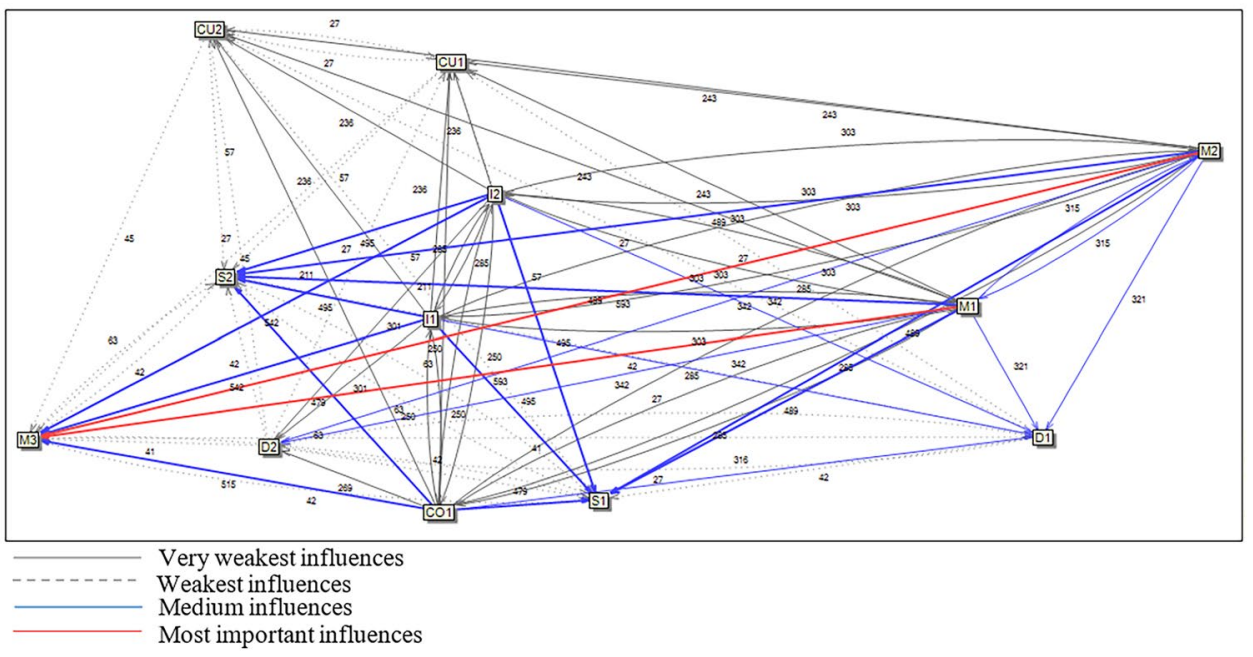

modular supply chain, they can also improve their ability to easily and quickly integrate new entities.

Our approach allows managers to know what the company should focus on in its reconfiguration process according to its objectives. The interactions identified between the factors allow facilitating and improving the reconfiguration process by identifying the factors that change the supply chain functions and those changing the supply chain structure. The aim of this paper is to guide managers to best practices to ensure the improvement of the supply chain

Table 12 Numerical factor weights of direct influences/dependencies

\begin{tabular}{llll}
\hline Factors & Direct influence & Factors & $\begin{array}{l}\text { Direct } \\
\text { dependency }\end{array}$ \\
\hline CO1 & 1538 & M3 & 1346 \\
I1 & 1538 & S1 & 1089 \\
I2 & 1538 & S2 & 1089 \\
M1 & 1410 & D1 & 833 \\
M2 & 1410 & M1 & 769 \\
M3 & 384 & M2 & 769 \\
D1 & 384 & D2 & 769 \\
D2 & 384 & I1 & 705 \\
CU1 & 384 & I2 & 705 \\
CU2 & 384 & CO1 & 641 \\
S1 & 320 & CU1 & 641 \\
S2 & 320 & CU2 & 641 \\
\hline
\end{tabular}

reconfigurability through modularity, integrability, convertibility, diagnosability, scalability, and customization. In our previous works, we have proposed a model to evaluate the supply chain reconfigurability; nevertheless, these works explore the characteristics independently. For this reason, this paper provides an effective tool for managers to use best practices to ensure reconfigurability through its six characteristics while integrating the interactions between them to optimize their reconfiguration process.

Table 13 Numerical factor weights for indirect influences/dependencies

\begin{tabular}{llll}
\hline Factors & Indirect influence & Factors & $\begin{array}{l}\text { Indirect } \\
\text { dependency }\end{array}$ \\
\hline M1 & 1958 & M3 & 1429 \\
M2 & 1958 & S1 & 1304 \\
I1 & 1880 & S2 & 1304 \\
I2 & 1880 & D1 & 775 \\
CO1 & 1752 & D2 & 735 \\
D1 & 95 & M1 & 694 \\
D2 & 95 & M2 & 694 \\
CU1 & 86 & I1 & 650 \\
CU2 & 86 & I2 & 650 \\
M3 & 75 & CO1 & 600 \\
S1 & 65 & CU1 & 580 \\
S2 & 65 & CU2 & 580 \\
\hline
\end{tabular}


Fig. 8 Factor classification

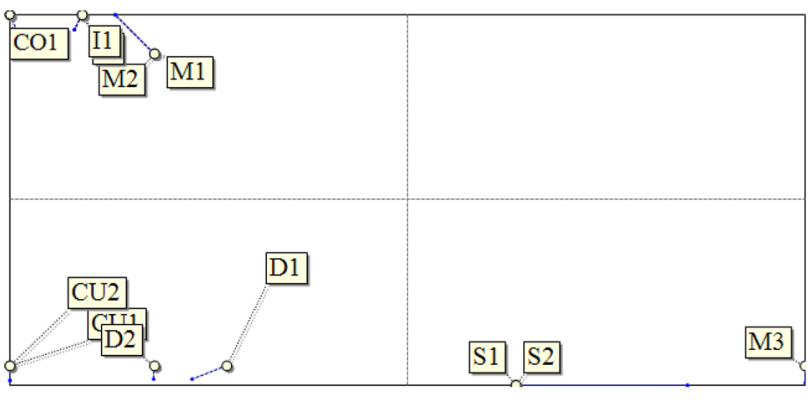

Fig. 9 The direct/indirect displacement map

Table 14 Classification of factors according to their dependencies on other factors

\begin{tabular}{lll}
\hline & Dependent factors & Independent factors \\
\hline Direct classification & $\mathrm{M} 3, \mathrm{~S} 1, \mathrm{~S} 2$ & $\mathrm{M} 1, \mathrm{M} 2, \mathrm{I} 1, \mathrm{I} 2, \mathrm{CO} 1$ \\
Indirect classification & $\mathrm{M} 3, \mathrm{~S} 1, \mathrm{~S} 2$ & $\mathrm{M} 1, \mathrm{M} 2, \mathrm{I} 1, \mathrm{I} 2, \mathrm{CO} 1$ \\
Intersection & $\mathrm{M} 3, \mathrm{~S} 1, \mathrm{~S} 2$ & $\mathrm{M} 1, \mathrm{M} 2, \mathrm{I} 1, \mathrm{I} 2, \mathrm{CO} 1$ \\
\hline
\end{tabular}

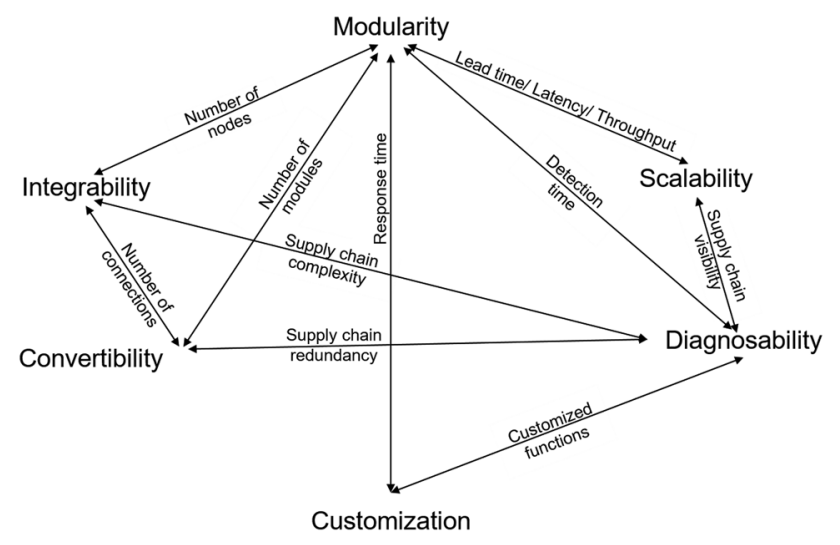

Fig. 10 Representation of the relationships between the characteristics of supply chain reconfigurability

\section{Conclusion}

Supply chain reconfiguration has recently become a crucial strategy to cope with disruptions and adapt to new market needs. The success of the reconfiguration strategy depends on ensuring its six characteristics (modularity, integrability, convertibility, diagnosability, scalability, and customization) that reduce the reconfiguration effort.

In this paper, the quantitative factors enabling to evaluate the degree of reconfigurability were identified from the literature and analyzed using the TISM approach and the MICMAC analysis. The influence of the identified factors on each other was studied to prioritize them. In fact, twelve factors related to the six previously mentioned characteristics were examined. Their influence was shown using a questionnaire that allowed constructing the influence matrix of the TISM approach. Based on the results obtained by the latter, the factors were classified into 4 levels according to their influences. Indeed, the number of modules, the number of intra- and inter-module interactions, the number of nodes, and the number of connections between them and the supply chain redundancy are the factors that influence other factors, but they are not influenced by them. This prioritization of factors was verified and validated by the MICMAC analysis through direct and indirect classifications of influences between factors. On the other hand, by interpreting these results, the characteristics were classified into two aspects (structural and functional). Modularity, integrability, and convertibility are related to the structural aspect, i.e., they allow changing essentially the design structure of the supply chain. However, the functional aspect of the RSC depends mainly on diagnosability, scalability, and customization.

These two identified dimensions are applicable to any type of supply chain because the identified factors can be related to all supply chains whatever their sector of activity, their type, their structures, etc. Indeed, ensuring modularity, integrability, and convertibility requires respectively the 
decomposition of the supply chain into a set of independent modules, reducing the structural complexity of the supply chain while ensuring redundant entities. These characteristics are generic and can be guaranteed in all supply chains to reconfigure their structures, as they do not depend on the type of activity.

The same for diagnosability, scalability, and customization, which are guaranteed respectively by improving the visibility of the supply chain information, increasing the throughput of products and orders realized in the supply chain, and increasing its customizable functions. These suggestions can be applied in all supply chains whatever their sectors of activity, which contributes to the reconfiguration of the supply chain functions.

The proposed model allowed classifying the quantitative factors evaluating the six reconfigurability characteristics according to their influence on each other. However, the attribution of weights to each characteristic in the evaluation of the degree of reconfigurability cannot be assigned using our model. Indeed, the importance of the characteristics changes as a function of the sector, the market disruptions, the customers' requirements, etc. In order to apply the results of our approach, we propose to study the example discussed in [20]. This case study dealt with reconfigurability in a pellet stove distribution company; thus, the results of our approach enable to improve this case study by integrating the identified interactions in order to optimize the reconfiguration processes. On the other hand, we propose to apply our results in companies that have found difficulties in dealing with the effects of COVID-19 on the market (transport companies, hypermarkets, etc.).

The proposed approach has two main limitations. First, the survey conducted to identify the interactions between the factors related to the six characteristics must be extended to include a larger number of experts. Second, this paper addresses the six characteristics of supply chain reconfigurability to improve its ability to adapt to new changes and cope with market disruptions. Nevertheless, it will be important to integrate other concepts that also address the improvement of supply chain performance in a changeable and uncertain environment, such as resilience, agility, and viability. In future work, we will focus on the importance of each characteristic in the reconfigurability assessment process by taking into consideration their influence on each other.

Data availability The authors have no data or supplementary material to declare but the data will be made available to reviewers if necessary. The authors confirm that the data supporting the findings of this study are available in the article.

Code availability No code to declare.

\section{Declarations}

Ethics approval Not applicable.

Consent to participate Not applicable.

Consent for publication Not applicable.

Conflict of interest The authors declare no competing interests.

\section{References}

1. Barbieri P, Elia S, Fratocchi L, Golini R (2019) Relocation of second degree: moving towards a new place or returning home? J Purch Supply Manag 25:100525. https://doi.org/10.1016/j.pursup. 2018.12.003

2. Robinson PK, Hsieh L (2016) Reshoring: a strategic renewal of luxury clothing supply chains. Oper Manag Res 9:89-101. https:// doi.org/10.1007/s12063-016-0116-x

3. Barbieri P, Boffelli A, Elia S et al (2020) What can we learn about reshoring after Covid-19? Oper Manag Res 13:131-136. https:// doi.org/10.1007/s12063-020-00160-1

4. Strange R (2020) The 2020 COVID-19 pandemic and global value chains. J Ind Bus Econ 47:455-465. https://doi.org/10.1007/ s40812-020-00162-x

5. Essex A, Subramanian N, Gunasekaran A (2016) The relationship between supply chain manager capabilities and performance: empirical evidence. Prod Plan Control 27:198-211. https://doi. org/10.1080/09537287.2015.1091519

6. Zidi H, Hamani N, Laajili C, Benaissa M (2021) A reconfiguration approach for a supply chain tracking platform. International Journal of Shipping and Transport Logistics: Inderscience Publishers

7. Dolgui A, Ivanov D, Sokolov B (2018) Ripple effect in the supply chain: an analysis and recent literature. Int J Prod Res 56:414-430. https://doi.org/10.1080/00207543.2017.1387680

8. Olivares-Aguila J, ElMaraghy W (2020) System dynamics modelling for supply chain disruptions. Int J Prod Res 1(19). https://doi. org/10.1080/00207543.2020.1725171

9. He J, Alavifard F, Ivanov D, Jahani H (2019) A real-option approach to mitigate disruption risk in the supply chain. Omega 88:133-149

10. Ho W, Zheng T, Yildiz H, Talluri S (2015) Supply chain risk management: a literature review. Int J Prod Res 53:5031-5069. https://doi.org/10.1080/00207543.2015.1030467

11. Hosseini S, Ivanov D, Dolgui A (2019) Review of quantitative methods for supply chain resilience analysis. Transport Res E-Log 125:285-307. https://doi.org/10.1016/j.tre.2019.03.001

12. Torabi SA, Baghersad M, Mansouri SA (2015) Resilient supplier selection and order allocation under operational and disruption risks. Transport Res E-Log 79:22-48. https://doi.org/10.1016/j. tre.2015.03.005

13. Slepniov D, Waehrens BV, Jørgensen C (2010) Global operations networks in motion: Managing configurations and capabilities. Oper Manag Res 3:107-116. https://doi.org/10.1007/ s12063-010-0032-4

14. Dolgui A, Ivanov D, Sokolov B (2020) Reconfigurable supply chain: the X-network. Int J Prod Res 58:4138-4163. https://doi. org/10.1080/00207543.2020.1774679

15. Tziantopoulos K, Tsolakis N, Vlachos D, Tsironis L (2019) Supply chain reconfiguration opportunities arising from additive manufacturing technologies in the digital era. Prod Plan Control 30:510-521. https://doi.org/10.1080/09537287.2018.1540052 
16. Chandra C, Grabis J (2016) Supply chain configuration: concepts, solutions, and applications, 2nd edn. Springer-Verlag, New York

17. Biswas $P$ (2017) Modeling reconfigurability in supply chains using total interpretive structural modeling. J Advances Mgmt Research 14:194-221. https://doi.org/10.1108/JAMR-09-2016-0071

18. Kelepouris T, Wong CY, Farid AM et al (2006) Towards a reconfigurable supply network model. In: Intelligent Production Machines and Systems. Elsevier pp 481-486

19. Zidi S, Hamani N, Kermad L (2021) New metrics for measuring supply chain reconfigurability. J Intell Manuf. https://doi.org/10. 1007/s10845-021-01798-9

20. Zidi S, Hamani N, Kermad L (2021) Use of fuzzy logic for reconfigurability assessment in supply chain: Case study. Int J Fuzzy Syst. https://doi.org/10.1007/s40815-021-01187-7

21. Maganha I, Silva C, Ferreira LMDF (2018) Understanding reconfigurability of manufacturing systems: an empirical analysis. J Manuf Syst 48:120-130

22. Koren Y, Heisel U, Jovane F, AL ET (1999) Reconfigurable manufacturing systems. CIRP Ann 48(2):527-540

23. Wiendahl HP, Heger CL (2004) Justifying changeability. A methodical approach to achieving cost effectiveness. J Manuf Sci Eng 6(1-2):33-40

24. Setchi RM, Lagos N (2004) Reconfigurability and reconfigurable manufacturing systems: state-of-the-art review. 529-535

25. Mehrabi MG, Ulsoy AG, Koren Y (2000) Reconfigurable manufacturing systems: key to future manufacturing I SpringerLink. J Intell Manuf 11:403-419

26. Elmaraghy HA (2005) Flexible and reconfigurable manufacturing systems paradigms. Int J Flex Manuf Syst 17(4):261-276

27. Koren Y, Shpitalni M (2010) Design of reconfigurable manufacturing systems. J Manuf Syst 29(4):130-141

28. Wei H, Wang ETG (2007) Creating strategic value from supply chain visibility- the dynamic capabilities view. 2007 40th Annual Hawaii International Conference on System Sciences 7-7

29. Zidi S, Hamani N, Kermad L (2022) Classification of reconfigurability characteristics of supply chain. In: Andersen A-L, Andersen R, Brunoe TD et al (eds) Towards sustainable customization: bridging smart products and manufacturing systems. Springer International Publishing, Cham, pp 72-79

30. Zidi S, Hamani N, Kermad L (2021) Reconfigurable supply chain performance: a bibliometric analysis. In: Camarinha-Matos LM, Boucher X, Afsarmanesh H (eds) Smart and sustainable collaborative networks 4.0. Springer International Publishing, Cham, pp 161-169

31. Battaglia D, Pohlmann C, Moura JB et al (2017) Leveraging elements to small business strategic networks: the perception of business partners. Int J Bus Excell

32. Harris E (2020) Effective strategies for sustaining small retail businesses. Walden Dissertations and Doctoral Studies

33. Haynes G, Brow JR (2016) An examination of financial patterns using the survey of small business finances

34. Gupta A, Muita S (2012) Relationship between entrepreneurial personality, performance, job satisfaction and operations strategy: an empirical examination. Int J Bus Manag 8:p86. https://doi.org/ 10.5539/ijbm.v8n2p86

35. Teller J, Kock A (2013) An empirical investigation on how portfolio risk management influences project portfolio success. Int $\mathbf{J}$ Project Manage 31:817-829. https://doi.org/10.1016/j.ijproman. 2012.11.012

36. Renna P (2013) Decision model to support the SMEs' decision to participate or leave a collaborative network. Int J Prod Res 51:1973-1983. https://doi.org/10.1080/00207543.2012.701773

37. Beauville A, Klement N, Gibaru O et al (2019) Identification of reconfigurability enablers and weighting of reconfigurability characteristics based on a case study. Procedia Manuf 28:96-101
38. Rösiö C, Aslam T, Srikanth KB, Shetty S (2019) Towards an assessment criterion of reconfigurable manufacturing systems within the automotive industry. Procedia Manufacturing 28:76-82

39. Biswas P, Kumar S, Jain V, Chandra C (2019) Measuring supply chain reconfigurability using integrated and deterministic assessment models. J Manuf Syst 52:172-183

40. Cheng X, Wan C, Qiu H, Luo J (2019) A measure for modularity and comparative analysis of modularity metrics. In: Huang GQ, Chien C-F, Dou R (eds) Proceeding of the 24th International Conference on Industrial Engineering and Engineering Management 2018. Springer Singapore, Singapore, pp 266-277

41. Farid AM (2014) Measures of reconfigurability and its key characteristics in intelligent manufacturing systems. J Intell Manuf 28:353-369. https://doi.org/10.1007/s10845-014-0983-7

42. Gumasta K, Kumar Gupta S, Benyoucef L, Tiwari MK (2011) Developing a reconfigurability index using multi-attribute utility theory. Int J Prod Res 49:1669-1683. https://doi.org/10.1080/ 00207540903555536

43. Haddou Benderbal H, Dahane M, Benyoucef L (2018) Modularity assessment in reconfigurable manufacturing system (RMS) design: an Archived Multi-Objective Simulated Annealing-based approach. Int J Adv Manuf Technol 94:729-749. https://doi.org/ 10.1007/s00170-017-0803-2

44. Hölttä K, Suh ES, de Weck O (2005) Tradeoff between modularity and performance for engineered systems and products. In: DS 35: Proceedings ICED 05, the 15th International Conference on Engineering Design, Melbourne, Australia, 15.-18.08.2005. (Accessed 18 Nov 2020) https://www.designsociety.org/publication/23113/ TRADE OFF+ BETWE EN + MODUL ARITY + AND + PERFORMANCE+FOR+ENGINEERED+SYSTEMS+AND+ PRODUCTS

45. Hölttä-Otto K, Chiriac NA, Lysy D, Suk Suh E (2012) Comparative analysis of coupling modularity metrics. J Eng Des 23:790 806. https://doi.org/10.1080/09544828.2012.701728

46. Wang GX, Huang SH, Yan Y, Du JJ (2016) Reconfiguration schemes evaluation based on preference ranking of key characteristics of reconfigurable manufacturing systems. Int J Adv Manuf Technol 89:2231-2249. https://doi.org/10.1007/s00170-016-9243-7

47. Zidi S, Hamani N, Kermad L (2021) Modularity metric in reconfigurable supply chain. In: Dolgui A, Bernard A, Lemoine D et al (eds) Advances in production management systems. Springer International Publishing, Cham, Artificial Intelligence for Sustainable and Resilient Production Systems, pp 455-464

48. Bouaissi A, Allaoui H, Jean-Christophe N (2015) La modularité produit et chaîne logistique dans un contexte collaboratif et durable : revue de littérature et cadre conceptuel. In: Xème Conférence Internationale : Conception et Production Intégrées. Tanger, Morocco

49. Wolters MJJ (1999) The business of modularity and the modularity of buisiness. Selbstverl, Rotterdam

50. Voordijk H, Meijboom B, de Haan J (2006) Modularity in supply chains: a multiple case study in the construction industry. Int J Oper Prod Manag 26:600-618. https://doi.org/10.1108/ 01443570610666966

51. Maler-Speredelozzi V, Koren Y, Hu SJ (2003) Convertibility measures for manufacturing systems. CIRP Ann 52:367-370. https://doi.org/10.1016/S0007-8506(07)60603-9

52. Chinnathai MK, Alkan B, Harrison R (2017) Convertibility evaluation of automated assembly system designs for high variety production. Procedia CIRP 60:74-79. https://doi.org/10.1016/j.procir. 2017.01.005

53. Sheffi Y, Rice JB Jr (2005) A supply chain view of the resilient enterprise. MIT Sloan Management Review 47

54. Serdarasan S (2013) A review of supply chain complexity drivers. Comput Ind Eng 66:533-540. https://doi.org/10.1016/j.cie.2012. 12.008 
55. Serdarasan S, Tanyas M (2012) Dealing with complexity in the supply chain: the effect of supply chain management initiatives. Social Science Research Network, Rochester, NY

56. Nguyen H, Onofrei G, Harrison N, Truong D (2020) The influence of cultural compatibility and product complexity on manufacturing flexibility and financial performance. Oper Manag Res 13:171-184. https://doi.org/10.1007/s12063-020-00163-y

57. Beaulieu M (2000) Définir et maîtriser la complexité des réseaux de logistique à rebours

58. Caridi M, Crippa L, Perego A et al (2010) Do virtuality and complexity affect supply chain visibility? Int J Prod Econ 127:372383. https://doi.org/10.1016/j.ijpe.2009.08.016

59. Luke E (1993) Defining and measuring scalability

60. Ball MO, Ma M, Raschid L, Zhao Z (2002) Supply chain infrastructures: system integration and information sharing. SIGMOD Rec 31:61-66. https://doi.org/10.1145/507338.507350

61. Durowoju O, Chan H, Wang X (2011) The impact of security and scalability of cloud service on supply chain performance. J Electron Commer Res 12
62. Zebardast M, Malpezi S, Taisch M (2013) Mass customization in supply chain level: development of a conceptual framework to manage and assess performance. In: Prabhu V, Taisch M, Kiritsis $\mathrm{D}$ (eds) Advances in production management systems. Sustainable Production and Service Supply Chains. Springer Berlin Heidelberg, Berlin, Heidelberg, pp 81-90

63. Chandra C, Kamrani A (2004) Mass customization. Springer, US, Boston, MA

64. Graman GA (2010) A partial-postponement decision cost model. Eur J Oper Res 201:34-44. https://doi.org/10.1016/j.ejor.2009.03. 001

65. Medini K (2013) Enterprise performance evaluation in the context of sustainable mass customization

Publisher's Note Springer Nature remains neutral with regard to jurisdictional claims in published maps and institutional affiliations. 